CASE REPORT

\title{
Left over bowels: an unique complication in a surviving twin
}

\section{A T George, S Varkey, A Kalam, N Surendran}

Postgrad Med J 2004;80:736-737. doi: 10.1136/pgmj.2004.023499

Conjoint twins have always been a surgical challenge. The authors report an unusual finding in a surviving epigastric heteropagus twin. A 17 year old boy who underwent laparotomy for acute intestinal obstruction revealed a blind ending but complete duplication of the large bowel and an accessory liver in the falciform ligament, along with a separate gall bladder but with fused bile ducts.

The findings suggest that the duplicated bowel loop and the accessory liver were remnants of the incomplete parasite twin, assimilated into the body of the autosite, which remained asymptomatic for 17 years. This case is being reported because of the uniqueness of the finding.

A 17 year old boy was referred in January 2002 with features of acute intestinal obstruction. He gave a history of surgery in childhood, details of which were not available at that time. Examination showed a grossly distended abdomen with a $15 \times 10 \mathrm{~cm}$ scar over the upper abdomen. Hernial sites and external genitalia were normal. Auscultation showed absent bowel sounds.

Biochemical and haematological parameters were normal Abdominal radiography showed multiple air-fluid levels suggestive of intestinal obstruction. Ultrasound of the abdomen showed a dilated bowel loop and a suspected duplication of the liver and gall bladder.

Exploratory laparotomy showed the abdomen to be filled with a distended large bowel loop that was densely adherent to the parietus. Further exploration revealed the abdomen to be in two compartments and separated by a layer of thick membrane.

The anterior compartment contained an enormously dilated and distended loop of large intestine measuring about $150 \mathrm{~cm}$ in length and $5-15 \mathrm{~cm}$ wide and ending blindly at both ends. It had a glistening surface with areas of haemorrhage and multiple congested blood vessels (fig 1). The lumen was filled with yellowish non-feculent fluid. The mucosa appeared flattened with multiple ulcers and whitish specks. Attached fatty tissue showed multiple lymph nodes and one of them appeared yellowish white with a cord-like structure. No mesentery or any definite vascular pedicle was seen. There was no evidence of any connection to the underlying normal bowel. The posterior compartment contained the normal stomach, small gut, and large bowel with normal peristaltic activity.

Further exploration revealed an accessory lobe of liver within the falciform ligament, separate from the normal liver (fig 2).There was a large vascular pedicle, which when traced, was seen to arise from the right hepatic artery of the normal liver. Two distinct gall bladders were also observed. However, there was fusion of the bile ducts at the common bile duct level. The rest of the viscera were normal. The duplicated large bowel was excised in toto.

Histopathological and microscopic examination of the resected specimen showed a dilated segment of large intestine with ulceration and inflammation of the wall. Lymph nodes in the fatty tissue showed reactive changes. The yellowish white cord-like structure showed attached testicular tissue with predominantly Sertoli cells.

The postoperative period was uneventful and the patient was discharged. He remains asymptomatic to date, but has refused further investigations to confirm the accessory liver and the vascular patterns.

On retrospective inquiry about the previous surgery, the boy was found to be the first case of epigastric heteropagus reported in the world ${ }^{1}$ and the first surgery was done in 1985. The incomplete twin, which was attached to the xiphisternum, had been surgically detached under local anaesthesia, and consisted of two lower limbs with pelvis and external genitalia. There were no peripheral pulsations and the femoral and the dorsalis pedis arteries were not palpable. Scrotal sacs on both sides were empty. The penis was underdeveloped and there was a blind ending tract from the urethral meatus. Pelvic bone and the lower limb were fully formed. No vertebral bodies were detected. Anatomicopathological study of the parasite showed a lack of innervation and limb musculature. Examination of the internal viscera showed that the rectum and bladder were absent. Histopathology of the genitalia showed fibromuscular tissue with the tract being lined by squamous epithelium.

Ultrasound examination-which was the only investigation available at that time-had failed to show up any abnormalities in the abdomen and so a formal laparotomy had not been done on the infant. The infant also had exomphalos major and talipes equinovarus deformity of the right foot. Surgical correction was done without any difficulty. The child grew up with the only remnants of the incident being two scars on the upper abdomen. The large intestinal bowel loop of the anterior compartment of the abdomen and the accessory lobe of liver and gall bladder are in all probability the leftover portions of the incomplete twin detached 17 years previously. The blind, large bowel duplication lay quiescent in the abdomen, for 17 years,

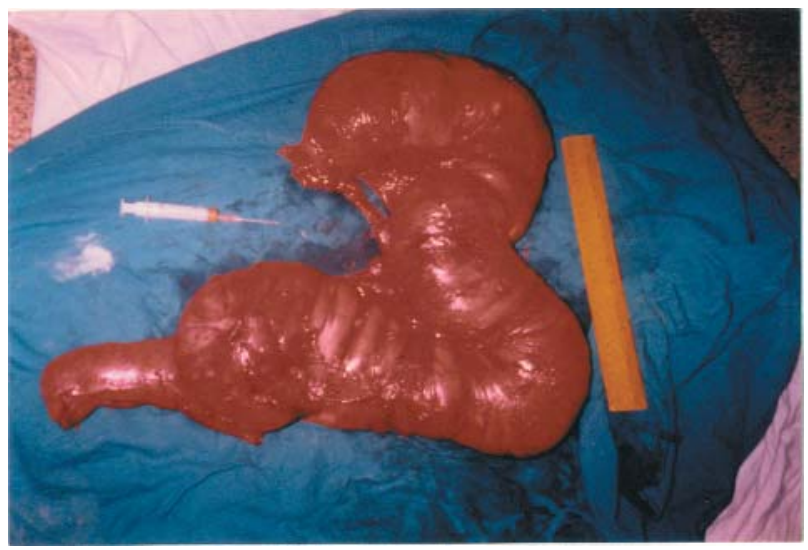

Figure 1 Distended bowel loop with aspirate. 


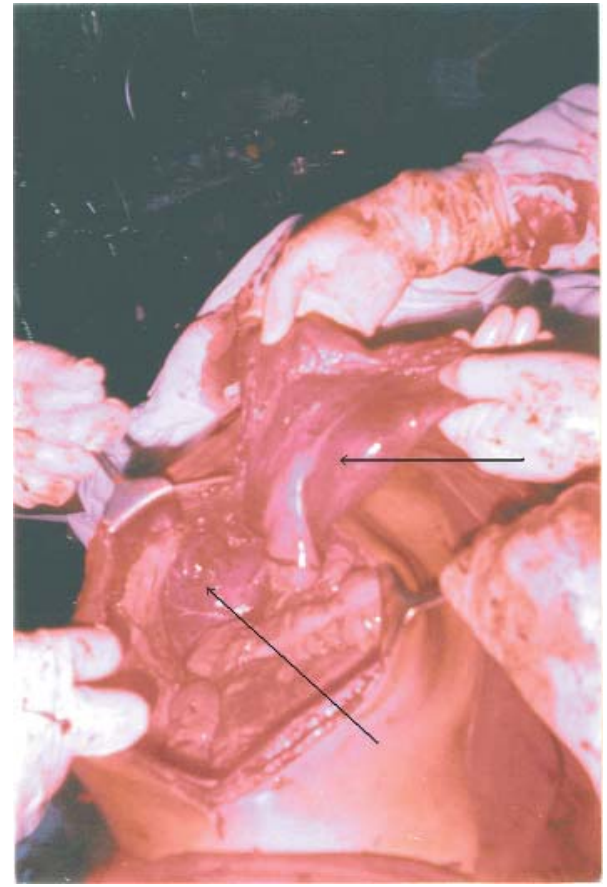

Figure 2 The two livers: the arrows point towards the normal liver and towards the accessory lobe in the falciform ligament which is lifted up.

until ulceration and inflammation supervened making it symptomatic.

\section{DISCUSSION}

Despite conjoint twinning being a very rare condition, it has always fascinated physicians, probably because of the challenge that it represents. Occurrence rates may vary from one in every 50000 to 100000 live births. ${ }^{2}$ Though the exact aetiology is unknown, the most commonly accepted theory is that this is triggered by an incomplete cleavage of the embryo that takes place at about 2 weeks of gestation. ${ }^{3}$ Thus, the twins share the same sex and chromosomal patterns, ${ }^{4}$ and depending upon the exact time of the split, can share body parts in addition to sharing the chorion and amnion. Twins are broadly classified into typical and atypical. ${ }^{4}$

Typical or diplopagus twins (equal and symmetrical conjoint twins) display nearly equivalent duplicate features; both the twins are complete individuals.

Atypical or heteropagus twins (unequal and asymmetrical), with an incidence of less than $10 \%$, display unequal duplication of features with varying degrees of development in each twin. It is usually characterised by an incomplete and parasitic portion, usually smaller than the well formed autosite. Epigastric heteropagus refers to the conjoint twin in which the parasite is attached to the epigastrium of the autosite. $^{5}$ Epigastric heteropagus twins differ in several ways from symmetrical conjoined twins. These include male preponderance, and no major connection of vessels, bowels, or bones. These significant characteristics suggest to the authors that the atrophy of one fetus may probably result in this interesting malformation. The possible pathogenesis could be an ischaemic atrophy of the body structure of the monozygotic conjoined twins at an early gestational age. ${ }^{5}$ There is very little information in the medical literature, but it is known that the complexity of the defect is variable with the number of functioning organs varying from case to case. ${ }^{6}$

Cases of epigastric heteropagus ${ }^{5}$ and twins with fused livers and hepatic biliary trees ${ }^{8}$ have been reported. Duplication of the large bowel occurs rarely with twinning conditions-however, there are no reports of duplication of the bowel or an accessory liver lobe or gall bladder in heteropagus twins. Reports of conjoint biliary tracts that were successfully separated have also been reported. ${ }^{9}$ Duplication of genitalia, urethra, small and large gut in a six legged goat was reported in 1997..$^{10}$

Such a unique complication occurring after a lapse of 17 years, in such an unusual case, has not been reported hitherto.

\section{Authors' affiliations}

A T George, S Varkey, A Kalam, N Surendran, Department Of General Surgery, Medical College Hospital, Thiruvananthapuram, Kerala State, India

Correspondence to: Dr A T George, Department of General Surgery, Torbay District General Hospital, Torbay, Devon TQ2 7AA, UK; anilthomasgeorge@hotmail.com

Submitted 6 May 2004

Accepted 10 June 2004

\section{REFERENCES}

1 Surendran N, Mani Nainan K, Paulose MO. An unusual case of caudal duplication. J Pediatr Surg 1986;21:924.

2 O'Neill JA, Holcomb GW III, Schnaufer L, et al. Surgical experience with thirteen conjoint twins. Ann Surg 1988;208:299-312.

3 Welch KJ, Randolph JG, Ratvitch MM, et al. Conjoint twins. Pediatric surgery. Chicago: IL, Year Book Medical, 1986:829-36.

4 Jain PK, Budhwani KS, Gambhir A, et al. Omphalopagus parasite: a rare congenital anomaly. J Pediatr Surg 1998;33:946-7.

5 Hwang EH, Han SJ, Lee SJ, et al. An unusual case of monozygotic epigastric heteropagus twinning. J Pediatr Surg 1996;31:1457-60.

6 Cury EK, Schraibman V. Epigastric heteropagus twinning. J Pediatr Surg 2001;36:E11.

7 Gupta DK, Lall A, Bajpai M. Epigastric heteropagus twins-a report of four cases. Pediatr Surg Int 2001;17:481-2.

8 Spitz L, Crabbe DC, Kiely EM. Seperation of thoraco-omphalopagus conjoint twins with complex hepato-biliary anatomy. J Pediatr Surg 1997;32:787-9.

9 Lobe TE, Oldham KT, Richardson CJ. Successful separation of a conjoined biliary tract in a set of omphalopagus twins. J Pediatr Surg 1989;24:930-2.

10 Otiang'a-Owiti G E, Oduor-Okelo D, et al. Duplication in a six legged goat. Anat Rec 1997;247:432-8. 